\title{
Makine Öğrenmesi İle Borsa Analizi
}

\author{
Mahmut Emir Arslan ${ }^{1}$, Pınar Kırc1 ${ }^{2 *}$ \\ ${ }^{1}$ Bursa Uludag University, Faculty of Engineering, Departmant of Computer Engineering, Bursa, Turkey, 031690062@ogr.uludag.edu.tr \\ ${ }^{2 *}$ Bursa Uludag University, Faculty of Engineering, Departmant of Computer Engineering, Bursa, Turkey, pinarkirci@uludag.edu.tr
}

(1st International Conference on Applied Engineering and Natural Sciences ICAENS 2021, November 1-3, 2021)

(DOI: 10.31590/ejosat.1012785)

ATIF/REFERENCE: Arslan, M.E., \& Kırc1, P. (2021). Makine Öğrenmesi İle Borsa Analizi. European Journal of Science and Technology, (28), 1116-1120.

\section{Öz}

Borsanın temel mantığı teknik analiz denilen matematiksel işlemlere, grafiklere ve bazı indikatörlere dayanmaktadır ve yatırımcılar işlemlerini bu grafik ve indikatörlerin ürettiği tahmin sonuçlarına göre gerçekleştirmektedirler. Bu projede makine öğrenimi ile geçmiş yıllara dair veriler kullanılarak bir sistem eğitilecek ve bu sistem gelecek günlerdeki bitcoin verilerini görsel hale getirip borsa hareketlerinin momentumuna göre kullanıcıya al ve sat sinyalleri üretecektir. Hedef olarak bugünün ve geleceğin değerli borsalarından birisi olan Bitcoin borsası ele alınacaktır. Doğrusal regresyon yöntemi ile Bitcoinin günlük grafikte en yüksek, en düşük, hacim ve arztalep verileri üzerinden al-sat sinyalleri üretilecektir. Bu veriler Quandl veritabanı aracılığıly Bitfinex bitcoin alım satım borsası tarafindan elde edilecektir.

Anahtar Kelimeler: Borsa, Doğrusal regresyon, Bitcoin, makine öğrenimi, Quandl veritabanı

\section{Stock Market Analysis with Machine Learning}

\begin{abstract}
The basic logic of the stock market is based on mathematical operations called technical analysis, graphics and some indicators. Investors perform their transactions according to the forecast results produced by these charts and indicators. In this project, a system will be trained using machine learning and data from the past years, and this system will visualize the bitcoin data in the coming days and generate buy and sell signals for the user according to the momentum of the stock market movements. As a target, the Bitcoin stock market, which is one of the valuable stock markets of today and the future, will be discussed. With the linear regression method, buysell signals will be generated over the highest, lowest volume and supply-demand data on the daily chart of Bitcoin. These data will be obtained by the Bitfinex bitcoin exchange through the Quandl database.
\end{abstract}

Keywords: Stock market, Linear regression, Bitcoin, machine learning, Quandl database 


\section{Giriş}

Modern döviz piyasası, Bretton Woods varlık yönetimi sisteminin dışına çıkıldığında şekillenmeye başladı. Bu pazarın eşsiz özellikleri şu şekildedir: günlük işlem hacminin büyüklüğü, coğrafi dağılım ve hafta içi günlerindeki sürekli çalışma. Forex piyasası, bir noktanın merkez alındığ 1 farklı büyüklükteki daireler olarak düşünülebilir. Sistemin merkezi piyasadaki en büyük bankalardan ve menkul kıymetlerden oluşur. İkinci daire ticari şirketler, yüksek risk barındıran yatırım fonları ve döviz tüccarları gibi diğer küçük katılımcılardan oluşur. İşlem yapılan katılımcı merkezden ne kadar uzaksa alım-satım yayılımı o kadar büyük olur [1].

21. yüzyılın başlarında hisse senedi fiyatlarının gelecek hareketlerini öngörmek adına birçok girişimde bulunuldu. Finansal piyasa, doğrusal olmayan oldukça karışık bir sistemdir. Sadece kendi düzenlemesi olan bir varyasyon olmamakla birlikte aynı zamanda siyaset, ekonomik durum ve yatırımcıların psikolojisi gibi diğer birçok faktörden etkilenir. Yapay sinir ağları kendi kendine organizasyon yapabilme, uyarlanabilmesi ve veri setleriyle eğitim yapilabilmesi dolayısıyla hisse senedi fiyatlarının dalgalanmalarını tahmin etmek için uygun bir araç durumundadır. Etkin piyasa hipotezine göre, finans piyasasında hisse senedi fiyatları halka açıldığında finans piyasasının gelecek hareketlerinin kesin olarak tahmin edilmesi imkansızdır. $\mathrm{Bu}$ analiz çoklu regresyon kullanan geleneksel çalışmalar için doğru kabul edilmektedir. Buna göre hisse senedi fiyatları, dinamik ve doğrusal olmayan ilişkiler ile finans piyasasında belirtilmektedir [2].

[3]'de yapılan çalışmada Bitcoin değerinin değişme oranının Google'da ve Wikipedia'da yapılan aramaların miktarıyla orantılı olduğu ifade edilmiştir. [4]'de sunulan çalışmada, Bitcoin değerinin değişim oranının medyada gördüğü ilgi ile popüler olması ve bitcoin üzerinde yapılan alım satım işlemlerinin hacimsel büyüklüğünden kaynaklı olduğu savunulmuştur. [5]'de yapılan çalışmada, Bitcoin ve altının sınırlı sayıda olmaları ve aralarında başka bir takım benzerlikler olduğu belirtilmiştir. [6]'da ise FTSE100, DOW30, SSE, S\&P500,NASDAQ gibi küresel piyasaların ve ayrıca altın, gümüş ve ham petrol gibi maden fiyatlarının bitcoin fiyatının değişimiyle orantılı olduğu belirtilmiştir.

Bitsgap, en çok tanınan, kripto para alım satım yapabilen makine öğrenmesi kullanılarak geliştirilmiş botlardan biridir. Kullanıcının bütün kripto para hesaplarını tek bir çatı altında toplar ve birleşik bir arayüz üzerinden işlem yapmasını sağlar. Bitsgap alım satım botu 25'ten fazla kripto para borsası üzerinde kullanılabilmekte ve kullanıcılar e-posta, Google veya Facebook hesapları üzerinden erişim sağlayabilmektedir. Otomatik alım satım işlemi sunduğu gibi kullanıcılara alım satım sinyalleri üreterek son kararı onlara bırakan bir sisteme de sahiptir. Arayüz üzerinden girilen alım satım emirleri yüksek güvenlik için 2048 bit şifreleme ile saklanmaktadır [7].

2003 yılında kurulan Trade Ideas, günlük işlemler açısından lider durumdaki bir platformdur. Yüksek olasılıklı işlem firsatları için $A B D$ ve Kanada'daki her hisse senedini geriye dönük test eden son teknoloji yapay zeka algoritmaları içerir. Trade Ideas başarılı görülen bir noktası her alım satım sinyalinin grafikte görsel olarak gösterilmesidir. Holly AI ismindeki bir algoritma ile Cleveland Biolabs hisse senetleri üzerinden 4 saatlik bir süre içerisinde \%25 oranında kar elde etmiştir. Holly Grail, Holly 2.0, Holly Neo, S\&P 500 ismindeki 4 yapay zeka algoritması ile yıllık olarak \%24 oranında kar sağlamıştır [8].
TrendSpider, hızla büyüyen bir alım satım şirketidir ve Dan Ushman tarafindan 2016 yılında kurulmuştur. Bu sistem yalnızca grafikler üzerinden görülmeyen eğilimleri tespit etmek için yapay zeka ve üstün matematiksel işlem gücü kullanmaktadır. TrendSpider, geçmiş veriler üzerinden eğitilirken trend çizgilerini ve fibonacci seviyelerini otomatik olarak üretebilmesi ile güçlü bir durumdadır [9].

MetaStock, 600'den fazla grafik ve göstergeye dayalı bir borsa teknik analiz hizmetidir ve Hisse senetleri, ETF'ler, endeksler, tahviller ve para birimlerinin grafiklerinin oluşturulmasını sağlar. Sistem, kullanıcı tarafından özel göstergeler üzerinden kullanıcı tarafından belirlenen hisse senetleri veya diğer yatırım araçları üzerinde alım satım yapabilmektedir. Genelde yeni başlayan veya orta düzey yatırımcılar tarafindan kullanılmaktadır [10].

Tickeron, örüntü tanımaya dayalı yapay zeka sistemlerini kullanır. Kullanılacak model seçildikten sonra bu model ile eşleşen hisse senetleri üzerinden oluşturulan veritabanı ve teknik analiz yöntemi kullanılarak alım satım işlemleri veya yön tahminleri üretilir [11].

\section{Materyal ve Yöntem}

Önerilen system, doğrusal regresyon yöntemini temel alacaktır ve Bitcoin'in günlük grafik üzerindeki sayısal değerleri doğrultusunda bir algoritma geliştirilerek bazı indikatörler yardımıyla da alım satım sinyalleri oluşturacaktır. Bu bölümde doğrusal regresyon yöntemi ve kullanılacak olan indikatörler ayrıntılı şekilde aşağıda açıklanmıştır.

Doğrusal regresyon, bir veya daha fazla tahmin üreten değişken ile bir sonuç değişkeni arasındaki ilişkiyi belirtir. Doğrusal regresyon genellikle tahmine dayalı analiz ve modelleme için kullanılır.

Göreceli güç endeksi, Welles Wilder Jr. Tarafından 1978'de geliştirilen bir finansal teknik analiz indikatörüdür. Belirli zaman aralığında bir hissenin yükseliş veya düşüş trendinde olduğunu ve bu hareketlerin ne kadar ivmeli olduğunu gösterir. Genel olarak tek başına kullanılmasa da ürettiği değerler üzerinden yatırımcıya alım-satım sinyalleri verebilir. RSI'ın en yaygın olarak kullanıldığı dönem sayısı 14'dür. Bunun anlamı incelenen grafiğe saatlik veya günlük olarak bakıldığında her saatin veya günün kapanış değerleri esas alınarak yüksek kapanış yapan dönemler, düşük kapanış yapan dönemlere bölünür ve göreceli güç elde edilir. Bu elde edilen değerin 1 fazlası 100'e bölünerek 100'den çıkarılır böylece her zaman 0-100 arasında bir değer alır. RSI değeri genel olarak 30-70 bantlarına göre değerlendirilir. 70 üstündeki değerlerde hisse üzerinde aşırı alım olduğu görülür ve satım sinyali verir. 30'un altındaki değerler ise aşırı satım olduğunu gösterir ve alım sinyali üretir.

MACD, Hareketli ortalamaların yakınsaması veya uzaksaması ismindeki bu indikatör 196011 yıllarda Gerald Appel tarafından geliştirilmiştir. Teknik analiz dünyasında en çok kullanılan indikatörlerin başında gelir.

\section{Bulgular}

Günümüzde kullanımı oldukça artan bitcoin borsası bir hayli hacimli hareketler yapmaktadır. Bunun anlamı, hisse fiyatlarının çok hızlı yükselmesi ve çok hızlı düşmesidir. Geliştirilen proje, bitcoin borsasında işlem yapan herkese fikir verme amaçlıdır.

Projede kullanılan yöntem sklearn kütüphanesinin doğrusal regresyon yöntemidir. Bu yönteme ilave olarak borsalarda en s1k 
kullanılan 2 momentum göstergesi 'MACD' ve 'RSI' göstergeleri eklenmiştir. Doğrusal regresyon yöntemi kullanılarak eğitilen sistem gelecek 11 günlük veri tahminlerini görsel hale getirerek kullanıcıya sunar. Bunun üstüne MACD ve RSI indikatörlerinden elde edilen veriler bir denklem üzerinde birleştirilerek bir hesaplamaya tabi tutulur ve denklem sonucuna göre kullanıcıya al, sat veya bekle sinyalleri iletir.

Sistemin veri kümesi 'Quandl' internet sitesi üzerinden 'Bitfinex' borsasındaki veriler ile sağlanmaktadır. Veri seti 2014 yılı Nisan ayının 15'inden günümüze kadar olan değerleri içerir [12]. Bu veriler bitcoinin günlük en yüksek, en düşük, kapanış, en yüksek-en düşük oranı, alım-satım oranı ve hacim değerleridir. Bu veri setine ek olarak doğrusal regresyon sınıfının '.predict()' fonksiyonu ile bitcoin borsasının gelecek dönem için üretilen tahmin değerleri ile 'Prediction' isimli yeni bir sütun oluşturulmuştur (Şekil 1).

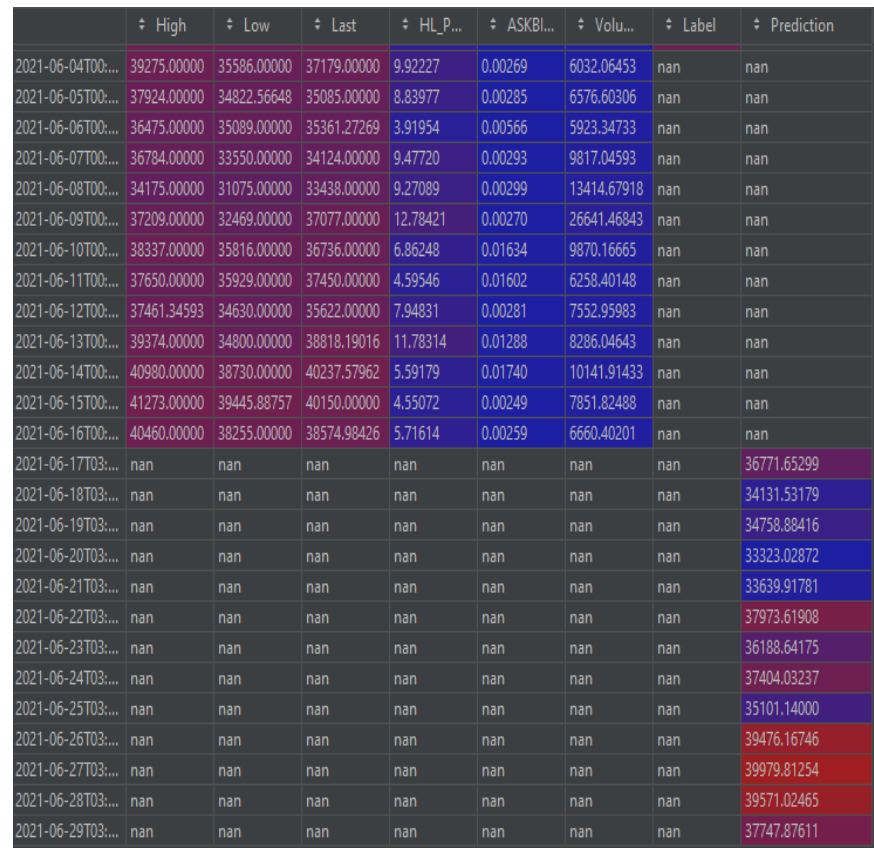

Şekil 1 Veri kümesi

\section{Sonuçlar ve Tartışma}

Veri setinin \%80'i sistemin eğitilmesi ve geri kalan \%20'si ise sistemin test edilmesi için kullanılmıştır. Yapılan test sonucu doğruluk oranının \%95,5 olduğu görülmüştür (Şekil 2).

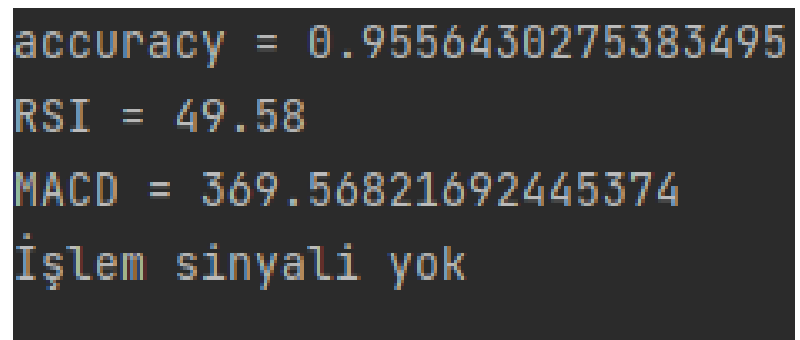

Şekil 2 Sonuç örneği

Sistemin test edilmesi LinearRegression() sınıfının '.score()' fonksiyonu ile gerçekleştirilmiştir. $\mathrm{Bu}$ fonksiyon bağımsız bir değişkenin doğrusal regresyon yöntemini kullanarak bağımlı değişkeni ne kadar belirtebildiğini ifade eder ve bu ölçüt belirtme katsayısı olarak adlandırılarak $R^{2}$ ile gösterilir. $R^{2}$ ' 0 ' ve ' 1 ' tamsayıları arasında bir reel sayı değeri ile regresyon modelinin doğruluk oranını ifade eder.

Borsa üzerinde tahmin değerleri üretilip veri setine aktarıldıktan sonra pyplot sınıfı ile bu verilerin görselleştirilmesi yapılmıştır (Şekil 3).

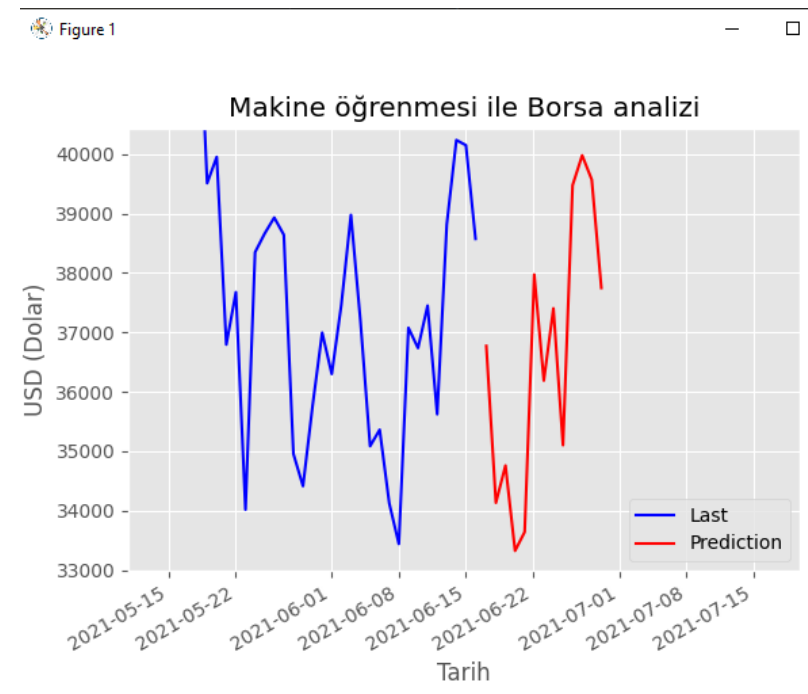

企 $\leftarrow \rightarrow \pm \sqrt{\mathbf{\Xi}}=$ 回 zoom rect

Şekil 3 Borsa analizi örneği

[13] Tarafından yapay sinir ağları kullanılarak uzun-kısa süreli bellek hücresi yöntemiyle geliştirilen sistem \%95'lik bir doğruluk oranına sahip olduğu halde geliştirici bu oranın yetersiz olduğunu savunmaktadır. Bitcoin borsasındaki çok yüksek hacimli ani değişimler göz önüne alındığında medyanın ve kimi tanınmış insanların spekülasyonları da işin içine katıldığında doğru bir düşüncedir. [6]'da yapılan çalışmada, kişileri rastgele orman makine öğrenmesi algoritmasını temel alarak geliştirdikleri bitcoin alım-satım programında çeşitli küresel ekonomik piyasaların hareketlerini ve teknolojik gelişmeler olarak adlandırdıkları bitcoin üretim hızı, Google ve Wikipedia'da yapılan aramaların sıklığı da projeye eklenmiştir. Sonuç olarak bu teknolojik ve ekonomik faktörler bitcoin fiyatı üzerinde büyük etkiye sahiptir.

Geliştirilen sistemin test sonuçlarından elde edilen \%95,5 oranındaki doğruluk oranına sahip olmasına rağmen, sistem geliştirildikten sonra yapılan incelemelerde görülmüştür ki bir sosyal medyada yapılan bir paylaşım sonrası bitcoinin değeri hızlı bir şekilde tahmin edilen değer aralığının dışına çıkmıştır. $\mathrm{Bu}$ incelemeye dayanarak diğer küresel borsalarda yapılan manipüle hareketleri \%5-\%10 civarında seyrederken bitcoin üzerinde bu manipüle hareketleri \%30'luk değişim oranının üstüne çıkabilmektedir. Bu da bitcoin borsasının diğer borsalara göre çok daha manipüle edilebilir olduğunu göstermektedir.

Projede, gelecek çalışmalar adına RSI ve MACD gibi daha fazla teknik analiz yöntemi eklenmesi yapılabilir. Bunun yanında medya ve tanınmış kişilerin spekülasyonlarına karşın bu spekülasyonları takip edip spekülasyon yönünde işlem açabilecek bir bot geliştirilebilir. Ayrıca projenin hedefi bitcoin ile sınırlı kalmayarak farklı borsalarda daha güvenli hisseler hedef olarak eklenebilir. 


\section{Kaynaklar}

[1] Evans, C., Pappas, K., \& Xhafa, F. (2013). Utilizing artificial neural networks and genetic algorithms to build an algo-trading model for intra-day foreign exchange speculation. Mathamatical and Computer Modelling(58), 1249-1266.

[2] Deng, W., \& Luo, Q. (2012). Stock Market Prediction Using Artificial Neural Networks. Advanced Engineering Forum(6-7), 1055-1060.

[3] Kristoufek, L. (2013). Bitcoin meets google trends and Wikipedia. Scientific Reports(3), 3415.

[4] Polasik, M., \& Piotrowska, A. (2015). Price fluctuations and the use of Bitcoin. International Journal of Electronic Commerce(20), 9-49.

[5] Dyhrberg, A. (2015). Bitcoin, gold and the dollar-A GARCH volatility analysis. Finance Research Letters(16), 85-92.

[6] Chen, W., Xu, H., \& Jia, L. (2021). Machine learning model for Bitcoin exchange rate prediction using economic and technology determinants. International Journal of Forecasting(37), 1300-1301.

[7] https://www.bitcoinhaber.net/otomatik-kripto-para-alim$\underline{\text { satim-botu-bitsgap-nedir }}$

[8] https://www.trade-ideas.com/

[9] https://victorytale.com/best-ai-stock-trading-software/

[10] https://www.liberatedstocktrader.com/ai-stock-trading/

[11] https://startupsavant.com/news/tickeron-launches-ai-robot

[12] Quandl.(2021). https://www.quandl.com/data/BITFINEX/BTCUSD-BTCUSD-Exchange-Rate 17 Haziran 2021

[13] Schmitz, J. (2020). https://towardsdatascience.com/thebeginning-of-a-deep-learning-trading-bot-part1-95accuracy-is-not-enough-c338abc98fc2 